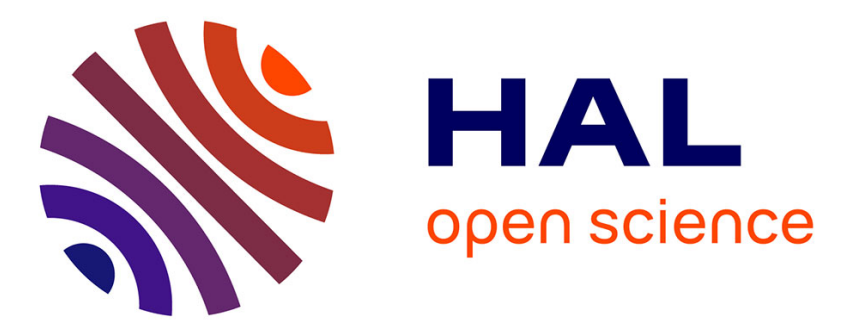

\title{
Improvement of YBCO Superconductor Magnetic Shielding by Using Multiple Bulks
}

Bruno Douine, Gaël Malé, Thierry Lubin, Smail Mezani, Jean Lévêque, Kévin Berger

\section{- To cite this version:}

Bruno Douine, Gaël Malé, Thierry Lubin, Smail Mezani, Jean Lévêque, et al.. Improvement of YBCO Superconductor Magnetic Shielding by Using Multiple Bulks. Journal of Superconductivity and Novel Magnetism, 2014, 27 (4), pp.903-907. 10.1007/s10948-013-2460-5 . hal-00917311

\section{HAL Id: hal-00917311 \\ https://hal.science/hal-00917311}

Submitted on 11 Dec 2013

HAL is a multi-disciplinary open access archive for the deposit and dissemination of scientific research documents, whether they are published or not. The documents may come from teaching and research institutions in France or abroad, or from public or private research centers.
L'archive ouverte pluridisciplinaire HAL, est destinée au dépôt et à la diffusion de documents scientifiques de niveau recherche, publiés ou non, émanant des établissements d'enseignement et de recherche français ou étrangers, des laboratoires publics ou privés. 


\title{
Improvement of YBCO superconductor magnetic shielding by using multiple bulks
}

\author{
B. Douine, G. Malé, T. Lubin, S. Mezani, J Lévêque, K. Berger
}

\begin{abstract}
HTS bulks present a high critical current density which can be used as magnetic shields. Previous works showed that BSCCO bulks can screen magnetic fields up to 0.1 T. For large scale applications like electrical machines, stronger magnetic field is usually needed. In so doing, (RE)BCO materials are more suitable since they can shield much higher magnetic fields. Another key issue concerns the size of the bulks. Nowadays, it is possible to manufacture $150-\mathrm{mm}$ diameter class cylindrical YBCO bulk. In order to get larger magnetic shielding areas, multiple bulk superconductors should be arrayed and stacked in layers. This paper presents experimental results on screening performances of layered YBCO pellets. These results are compared with $2 \mathrm{D}$ simulations. The experiments are carried out at $77 \mathrm{~K}$ under external magnetic fields of $150 \mathrm{mT}$. Different topologies are considered single layer configuration with 9 square pellets and double layer configuration with respectively 9 and 4 square pellets. Experimental and simulation results show that a checkerboard of one layer configuration doesn't fully shield the external magnetic field. Improved shielding properties are obtained when the double-layer configuration is used.
\end{abstract}

Index Terms-Superconducting shielding, HTS bulks, Superconducting motor

\section{INTRODUCTION}

B ULK SUPERCONDUCTORS allow screening high magnetic field. Indeed, during the shielding process a superconducting pellet naturally creates eddy currents inside the materiel in opposition with the change of the external magnetic field. This behavior of bulk is useful within the framework of electrical motors [1-5]. The kind of motor using these HTS screens developed in our laboratory is based on the concentration of magnetic flux between HTS screens. You can see in Fig. 1 the structure of inductor of this motor where the direction of the flux density is represented by black arrows. The inductor providing the excitation field consists of two solenoids fed with opposite currents. They create a flux density distribution with a high value of radial component between the two coils.

Superconducting YBCO Bulk plates [4] are located between the two solenoids thus the flux density is maximum between the plates and minimum behind them. In the previous articles [1-5] the studies have been done for electrical motors less than $50 \mathrm{~kW}$. In our laboratory the feasibility of making large screens for engines of greater power to over $1 \mathrm{MW}$ is studied.

This work was supported in part by the Direction Générale de l'Armement (DGA).

B. Douine, G. Male, T. Lubin, S. Mezani, J Leveque, K. Berger are with University of Lorraine, Groupe de Recherche en Electrotechnique et Electronique de Nancy, 54506 Vandoeuvre, France (e-mail: bruno.douine@univ-lorraine.fr, thierry.lubin@univ-lorraine.fr, male.gael.hr@gmail.com, jean.leveque@univ-lorraine.fr, kevin.berger@univ-lorraine.fr).
Usually greatest size of YBCO bulks is around de 10x10x2 $\mathrm{cm}^{3}$. In our case screen widths of more than $1 \mathrm{~m}$ are desired. We propose to do this kind of very wide superconducting screen with a checkerboard of high superconducting superconductor (HTS) pellets [6]. Three kinds of topologies are studied (Fig.2), only one HTS bulk, a checkerboard of 9 square HTS pellets and a double layer of HTS checkerboard, the first one with 9 square pellets and the second one with 4 square pellets. Experimental measurement of magnetic field has been done and compared with 2D simulations. In the last two cases there are magnetic leaks between the pellets. To appreciate the shielding performance of these different topologies the average of the magnetic field should be calculated.

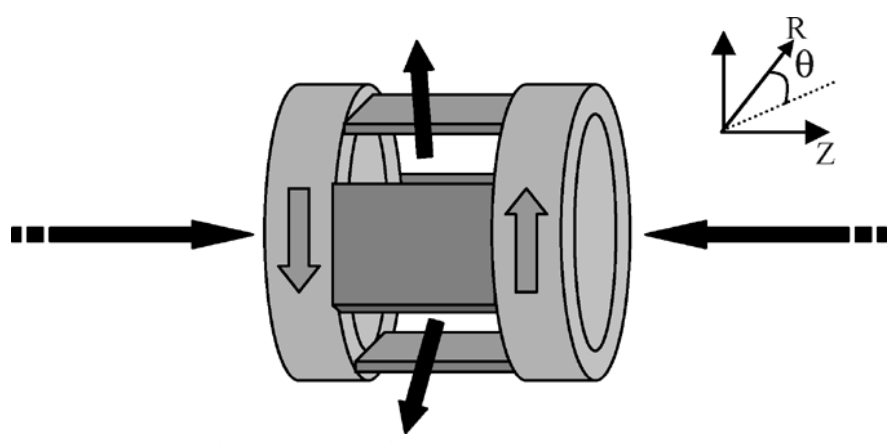

Fig. 1. Structure of the inductor of the motor using HTS screens.

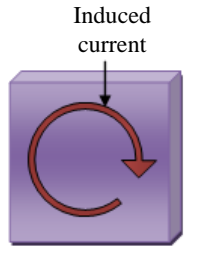

a)

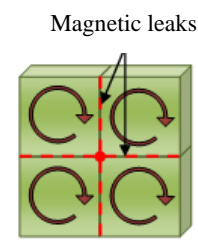

b)

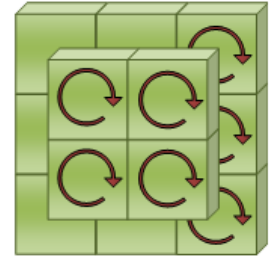

c)
Fig. 2. Topologies of superconducting large screens proposed: (a) one HTS bulk (b) Checkerboard (c) checkerboard with two layers.

\section{EXPERIMENTAL SET-UP AND RESULTS}

\section{A. Experimental set-up}

In this section, we carry out experimental tests on pellets YBCO. We study the possibility of creating magnetic large screens by combining basic reduced size pellets. The pellets are combined to form a checkerboard of one or two layers. The tests are performed at $77 \mathrm{~K}$ and applied magnetic fields of the order of $0.1 \mathrm{~T}$. The size of HTS pellets used are for the HTS bulk, $30 \times 30 \times 5 \mathrm{~mm}^{3}$, for the 9 and 4 HTS pellets, $10 \times$ 
$10 \times 5 \mathrm{~mm}^{3}$

The superconducting pellets are positioned on the outside of the field coil (Fig. 3). To increase slightly the value of the magnetic field, we added a ferromagnetic core in the coil. Using a Hall probe $(1.25 * 0.5 \mathrm{~mm}$ active area), attached to the arm of a XY 2-axis table, the map of the magnetic field $B$ at the surface of the superconducting screen studied is measured.

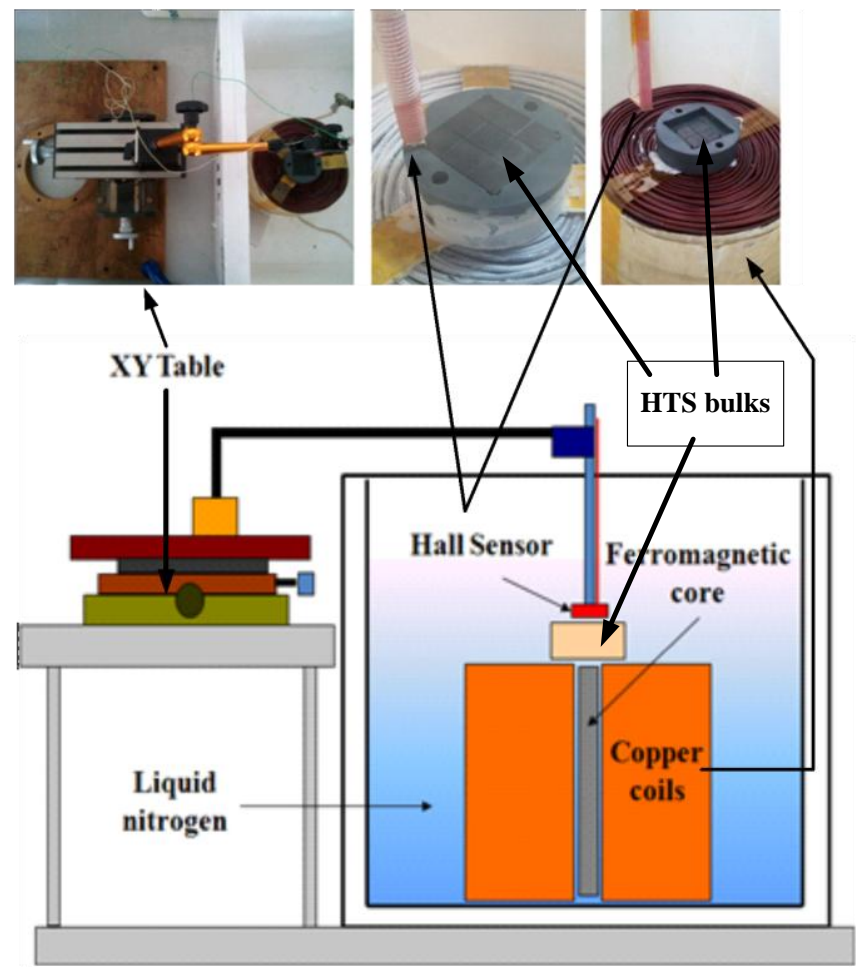

Fig. 3.Experimental set-up.

\section{B. Experimental results}

Hall mapping measurements are represented in Fig. 4:

Case 1: Warm measurements $\left(T>T_{C}\right)$, the superconducting pellets are not cooled below their critical temperature so it can be considered as an experiment without HTS pellet because for this temperature HTS bulks are like "unseen".

Case 2: Cold measurement $\left(T<T_{C}\right)$ for the checkerboard of 9 pellets on one layer

Case 3: Cold measurement $\left(T<T_{C}\right)$ for the checkerboard of 9 pellets on the top layer with the addition of the checkerboard of 4 pellets on the bottom

In case 1 a normal induction almost uniformly about 150 $\mathrm{mT}$ on the surface of the uncooled superconductor is observed. In case 2, areas of high magnetic field concentration are present between pellets. In the case 3 these areas are also present but with lower magnetic field (Fig. 4).

Different magnetic field concentrations that were previously experimentally observed between the pellets are schematically described on Fig. 5. That means that Fig. 5 is a simplified resume of what is represented on Fig. 4.

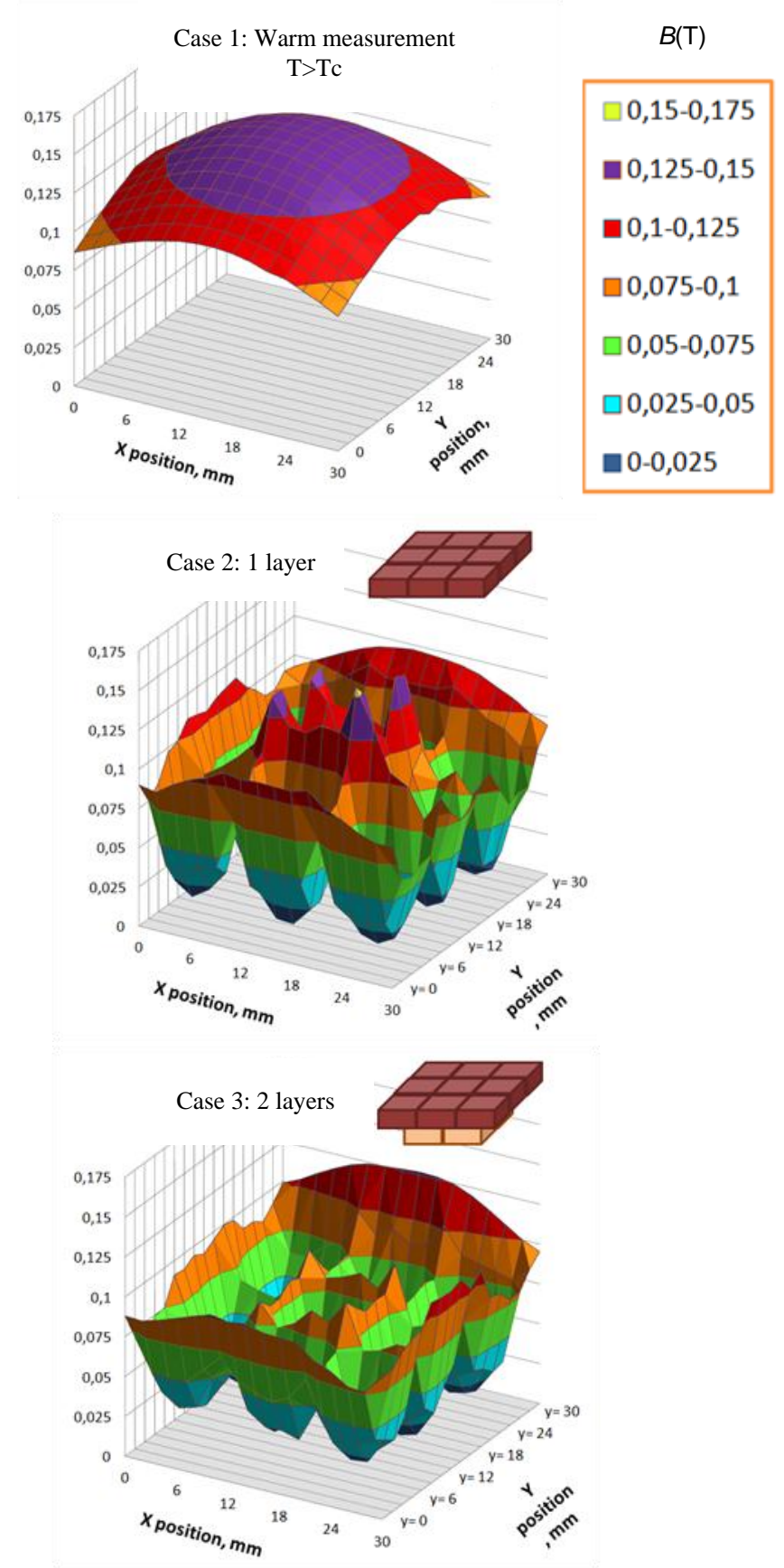

Fig. 4. Experimental results of magnetic field measurement for one HTS bulk , one checkerboard layer and assembly of two checkerboard layers.

In case 2 there is a strong magnetic field concentration at the internal angles of the pellets. Maximal values of the magnetic field in the internal angles of pellets are equivalent to values measured in case 1 . So shielding is only partial. In case 2 there are still zero magnetic field regions at the centers of the pellet what is the expected result for this kind of superconducting shield. In case 3 , with second layer of added pellets, there is a magnetic field concentration at the internal angles of the pellets but much lower than in case 2 . In cases 3 there are also zero magnetic field regions at the centers of the pellet. In case 3 shielding is also partial but more efficient in 
terms of maximal magnetic field and magnetic flux. This behavior is because the induced currents cannot flow between two superconducting pellets and are only inside the pellets (Fig. 2). In term of magnetic flux we observe a reduction of $50 \%$ in the case 2 with one layer and a reduction of $60 \%$ in the case 3 . Adding an additional layer increases screening by the attenuation of magnetic field peak concentration.

Case 2

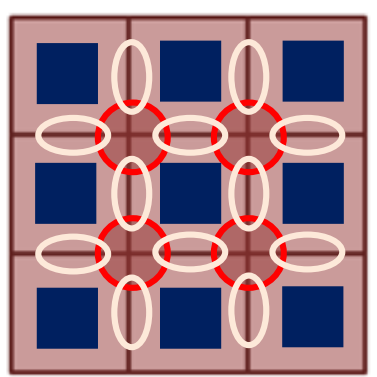

\begin{tabular}{|ccc|}
\hline $\begin{array}{l}\text { Weak } \\
\text { magnetic } \\
\text { field }\end{array}$ & $\begin{array}{c}\text { Strong } \\
\text { magnetic } \\
\text { field }\end{array}$ & $\begin{array}{c}\text { Zero } \\
\text { magnetic } \\
\text { field }\end{array}$ \\
\hline
\end{tabular}

Fig. 5. Illustration of the concentration of the magnetic field for the two topologies display: a layer or two layers.

\section{2D SIMULATIONS}

A 2D simulation of the multiple bulk screening is performed in this study because it is relatively easy to do it with commercial software, COMSOL 4.1. Up to now the same simulations in 3D are not possible in our lab although it seems more realistic and available. However this 2D approach allows us to quickly compare the different structures of screening capabilities.

In these $2 \mathrm{D}$ simulations the applied magnetic field $B_{a}$ is created by two conductors used similar to the used copper coil (Fig. 6). Then, the superconductor pellets is considered in the $x y$ plane with a sufficiently great length. The HTS bulks and the two conductors are considered infinitely long in the $z$ direction. The characteristics of the HTS bulks are given on table 1 . In this $2 \mathrm{D}$ geometry experimental case 2 (Fig. 4) with one layer of 9 bulks corresponds to a layer of 3 bulks (Fig.7) and experimental case 3 (Fig. 4) with two layers (9+4 bulks) corresponds to two layers with 3 and 2 bulks (Fig.7). Warm measurement (case 1) is considered as a numerical simulation without HTS bulk (Fig.7).

The field profiles can be computed by Faraday's law, Ampere's theorem and constitutive laws of superconducting material usually used for numerical simulation:

$$
\begin{aligned}
& \nabla \times \vec{E}=-\frac{\partial \vec{B}}{\partial t} \\
& \nabla \times \vec{B}=\mu_{0} \vec{J} \\
& E=\rho(J) . J \text { with } \rho(J)=\frac{E_{C}}{J_{C}}\left(\frac{|J|}{J_{C}}\right)^{n-I}
\end{aligned}
$$

$E$ is the electric field, $J$ is the current density, $\mu_{0}$ is the

TABLE I. CHARACTERISTICS OF HTS BULKS USED

\begin{tabular}{||l||l||}
\hline HTS material used & YBCO \\
\hline \hline Critical current density $J_{C}$ & $1.10^{8} \mathrm{~A} \cdot \mathrm{m}^{-2}$ \\
\hline \hline Exponent $n$ & 15 \\
\hline
\end{tabular}

permeability and $\rho$ is the resistivity. $n$ is the exponent of the power law $E(J)$.

To allow computing convergence a small value $\rho_{0}$, equals $1 \mathrm{e}^{-3} \times E_{C} / J_{C}$, is added to $\rho(J)$ [7]. A characteristic $J C(B)$ of the superconductor in liquid nitrogen [8] is used. The value of $n$ is fixed to 15 that is a realistic value for HTS at $77 \mathrm{~K}$.

We consider a two-dimensional problem in the $x y$ plane (Fig.6). The current density and then the electric field have only one component directed along the $\mathrm{z}$ axis and depend only on the $\mathrm{x}$ and $\mathrm{y}$ coordinates:

$$
\begin{aligned}
& \vec{J}=J_{Z}(x, y) \cdot \vec{e}_{z} \\
& \vec{E}=E_{Z}(x, y) \cdot \vec{e}_{z}
\end{aligned}
$$

Then the magnetic field has two components:

$$
\vec{B}=B_{x}(x, y) \cdot \vec{e}_{x}+B_{y}(x, y) \cdot \vec{e}_{y}
$$

Using (1) (2) and (3), utilization of PDE interface of COMSOL 4.1 is possible as follows:

$$
\left\{\begin{array}{l}
\frac{\partial B_{x}}{\partial t}+\frac{\partial E_{z}}{\partial y}=0 \\
\frac{\partial B_{y}}{\partial t}-\frac{\partial E_{z}}{\partial x}=0 \\
J_{z}=\frac{1}{\mu_{0}}\left(\frac{\partial B_{y}}{\partial x}-\frac{\partial B_{x}}{\partial y}\right) \\
E_{z}=\rho\left(\left|J_{z}\right|\right) J_{z}
\end{array}\right\}
$$

The applied magnetic field $B_{a}(t)$ is an increasing ramp from zero of around one minute duration:

$B_{a}(t)=\frac{\widehat{B}_{a}}{60} t$

Then the maximum value of $B_{a}$ at the center of the copper coil is chosen to get a similar distribution of the magnetic field as in the experimental part (Fig. 4 Case 1) without HTS bulk (Fig. 7).

The magnetic field, to the output of the coil without HTS bulk (Fig.7), reaches between 150 and $200 \mathrm{mT}$ at the position of the pellet.

After the addition of a pellet the magnetic field distribution changes. At the position considered on Fig. 8 the magnetic field is almost zero behind the superconducting pellet (Fig. 7). Instead, a concentration of the magnetic induction is visible on the vertical sides of the superconducting pellet (Fig. 7). You can see in Fig. 7 and 8 that there is a very low penetration of the magnetic field at the edge of the pellet. The use of a segmented bulk retains virtually no induction behind the HTS bulks, but a high concentration of magnetic induction appears between the bulks especially with one layer. Here again, we 
note a very low penetration of the magnetic field on the edge of different pellets. Finally, the addition of a second layer of pellets reduces the maximum value of magnetic induction between the pellets approximately from $0.5 \mathrm{~T}$ to $0.3 \mathrm{~T}$.

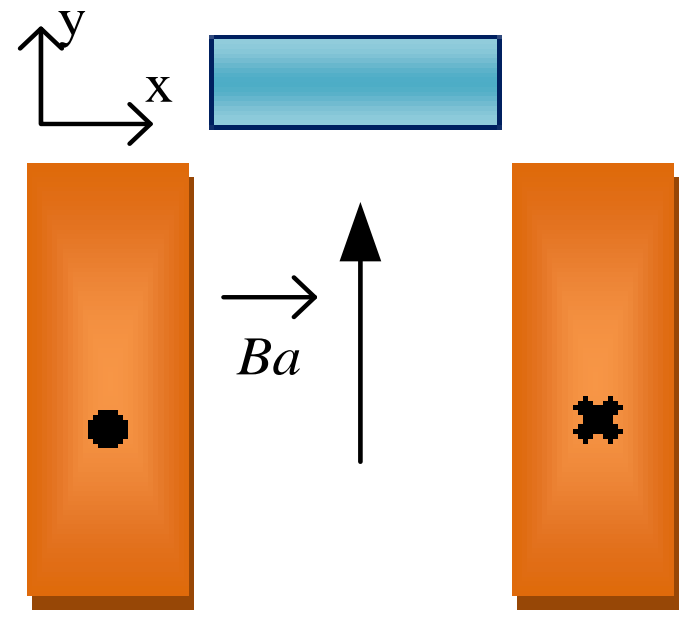

Fig. 6. Geometrical configuration of the 2D simulation.

\section{CONCLUSION}

In this paper the screening properties of YBCO bulks in a checkerboard shaped configuration are studied. It has been shown that a checkerboard of one layer configuration made from nine superconducting pellets doesn't fully shield the external magnetic field. Improved shielding properties are obtained when the double-layer configuration is used.

\section{ACKNOWLEDGMENT}

This work was supported in part by the Direction Générale de l'Armement (DGA).

\section{REFERENCES}

[1] P. Masson, D. Netter, J. Leveque, A. Rezzoug, " Experimental Study of a New Kind of Superconducting Inductor", I.E.E.E. Transactions on Applied Superconductivity, Vol. 13, N², June 2003, pp 2239-2242.

[2] D. Netter, J. Leveque, E. Ailam, B. Douine, A. Rezzoug, P. Masson, "Theoretical study of a new kind HTS motor", I.E.E.E. Trans. on Appl. Supercond., vol.15(2), pp.2186-2189, 2005

[3] A. Rezzoug, J. Leveque, B. Douine, S. Mezani, "Superconducting machines", published in "Non-conventional electrical machines", Wiley, pp.191-255, 2012.

[4] E. Ailam, D. Netter, J. Leveque, B. Douine, P. Masson, A. Rezzoug, "Design and Testing of a Superconducting Rotating Machine", I.E.E.E. Trans. on Appl. Supercond., vol.17(1), pp.27-33, 2007.

[5] R. Moulin, J. Leveque, L. Durantay, B. Douine, D. Netter, A. Rezzoug, "Superconducting Multi-Stacks Inductor for Synchronous Motors Using the Diamagnetism Property of Bulk Material," I.E.E.E. Trans. on Industrial Electronics, vol. 57, no. 1, pp. 146-153, 2010

[6] Y. Terao, M. Sekino, H. Ohsaki, H. Teshima, et M. Morita, « Magnetic Shielding Characteristics of Multiple Bulk Superconductors for Higher Field Applications », IEEE Transactions on Applied Superconductivity, vol. 21, $\mathrm{n}^{\circ} .3$, p. 1584-1587, juin. 2011.

[7] F. Sirois, F. Grilli, "Numerical considerations about using FEM to compute AC losses in HTS," IEEE Trans. On App. Supercnd., vol. 18, $\mathrm{n}^{\circ} 3,2008$.
[8] N. H. Babu, T. D. Withnell, K. Iida, et D. A. Cardwell, « Strongly Coupled Artificial Bulk HTS Grain Boundaries With High Critical Current Densities », IEEE Transactions on Applied Superconductivity, vol. 17, no. 2, p. 2949-2952, juin. 2007.
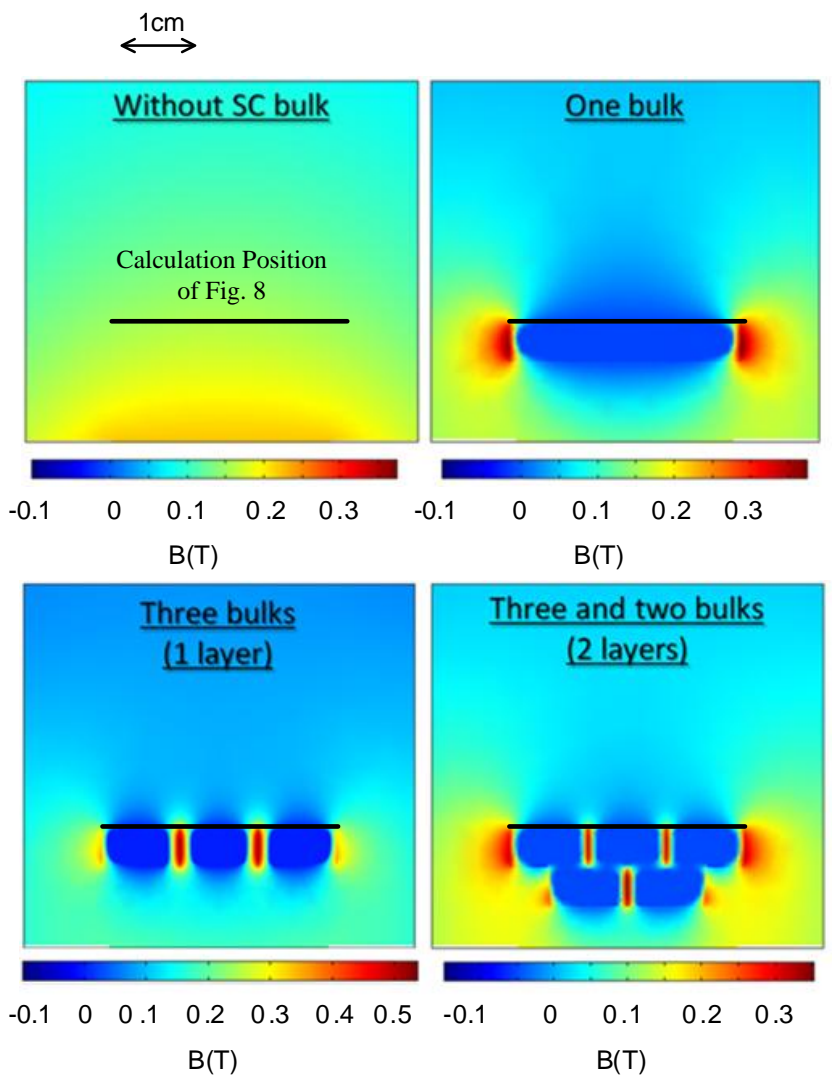

$\begin{array}{rrrr}-0.1 & 0 & 0.1 & 0.2 \\ & & B(T)\end{array}$

$\mathrm{B}(\mathrm{T})$

Fig. 7. 2D simulation of magnetic field without HTS bulk, for one HTS bulk, one layer and two layers of HTS bulks.

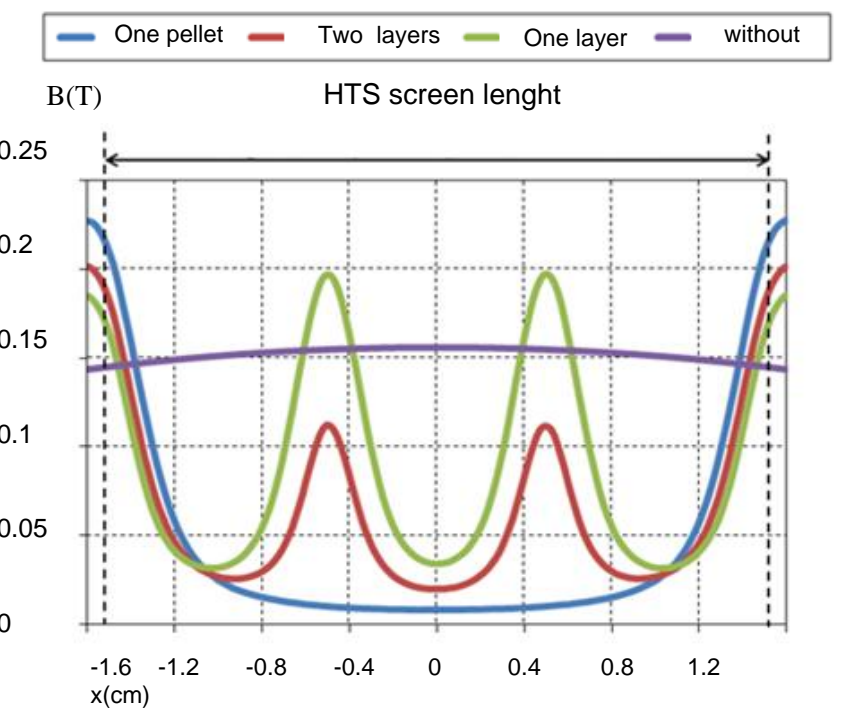

Fig. 8. Magnetic field calculated at the position shown in Fig. 7 without HTS bulk, for one HTS bulk, for one layer and for two layers of HTS bulks. 